\title{
The addition of locust bean gum but not water delayed the gastric emptying rate of a nutrient semisolid meal in healthy subjects Gassan Darwiche*1, Ola Björgell ${ }^{2}$ and Lars-olof Almér ${ }^{1}$
}

Address: ${ }^{1}$ Department of Internal Medicine, University of Lund, Malmo University Hospital, Sweden and ${ }^{2}$ Department of Radiology, University of Lund, Malmo University Hospital, Sweden

Email: Gassan Darwiche* - gassandarwiche@yahoo.com; Ola Björgell - ola.bjorgell@ rontgen.mas.lu.se; Lars-olof Almér - LarsOlof.Almer@medforsk.mas.lu.se

* Corresponding author

Published: 06 June 2003

BMC Gastroenterology 2003, 3:12
Received: 05 February 2003

Accepted: 06 June 2003

This article is available from: http://www.biomedcentral.com/I47/-230X/3/I2

(C) 2003 Darwiche et al; licensee BioMed Central Ltd. This is an Open Access article: verbatim copying and redistribution of this article are permitted in all media for any purpose, provided this notice is preserved along with the article's original URL.

\begin{abstract}
Background: Most of the previous studies regarding the effects of gel-forming fibres have considered the gastric emptying of liquid or solid meals after the addition of pectin or guar gum. The influence of locust bean gum, on gastric emptying of nutrient semisolid meals in humans has been less well studied, despite its common occurrence in foods. Using a standardised ultrasound method, this study was aimed at investigating if the gastric emptying in healthy subjects could be influenced by adding locust been gum, a widely used thickening agent, or water directly into a nutrient semisolid test meal.
\end{abstract}

Methods: The viscosity of a basic test meal ( $300 \mathrm{~g}$ rice pudding, $330 \mathrm{kcal}$ ) was increased by adding Nestargel $(6 \mathrm{~g}, 2.4 \mathrm{kcal})$, containing viscous dietary fibres $(96.5 \%)$ provided as seed flour of locust bean gum, and decreased by adding $100 \mathrm{ml}$ of water. Gastric emptying of these three test meals were evaluated in fifteen healthy non-smoking volunteers, using ultrasound measurements of the gastric antral area to estimate the gastric emptying rate (GER).

Results: The median value of GER with the basic test meal (rice pudding) was estimated at $63 \%$, (range 47 to $84 \%$ ), (the first quartile $=61 \%$, the third quartile $=69 \%$ ). Increasing the viscosity of the rice pudding by adding Nestargel, resulted in significantly lower gastric emptying rates $(p<$ 0.01 ), median GER $54 \%$, (range 7 to $71 \%$ ), (the first quartile $=48 \%$, the third quartile $=60 \%$ ). When the viscosity of the rice pudding was decreased (basic test meal added with water), the difference in median GER $65 \%$, (range 38 to $79 \%$ ), (the first quartile $=56 \%$, the third quartile = 7I \%) was not significantly different $(p=0.28)$ compared to the GER of the basic test meal.

Conclusions: We conclude that the addition of locust bean gum to a nutrient semisolid meal has a major impact on gastric emptying by delaying the emptying rate, but that the addition of water to this test meal has no influence on gastric emptying in healthy subjects.

\section{Background}

Many factors are believed to affect gastric emptying, including the volume and energy density of the meal and its viscosity and particle size [1]. The blood glucose level, 
hyperinsulinemia, gender, certain drugs [2], body size [3], meal temperature [4], and smoking [5] could be other influencing factors. Dietary fibers has a number of metabolic effects, some of which are potentially useful in treating pathological conditions such as obesity, hypercholesterolaemia, and diabetes mellitus $[6,7]$. They include a range of relatively poorly digested food substances mainly composed of non-starch polysaccharides. Generally dietary fibers sources can be grouped into two major types due to their quite different physiological effects: soluble (viscous and fermentable), and insoluble (non-viscous, slowly fermentable). Viscous gel-forming fiber's includes pectins and gums and these natural colloids are multi-branched hydrophilic substances having the capability of absorbing water readily and forming viscous solutions. Several studies indicate that the addition of viscous soluble fiber's to the meal [8-12] as well as fibre naturally present in food [13] reduce the gastric emptying rate and the glycemic response to a test meal. A delayed absorption due to increased viscosity of the intestinal content has been suggested to partly explain the reduced glycemic response in other studies [14,15]. Despite the capability of the water soluble dietary fibres to form viscous solutions, it is not known if the reduction in gastric emptying is due to increased meal viscosity or effects on antroduodenal coordination by alteration in duodenal feedback from mucosal receptors. Most of the previous studies regarding the effects of gel-forming fibres have considered the gastric emptying of liquid or solid meals after the addition of pectin or guar gum. The influence of locust bean gum, on gastric emptying of nutrient semisolid meals in humans has been less well studied, despite its common occurrence in foods.

Torsdottir [16] have shown that an addition of $300 \mathrm{ml}$ of water as a drink with the meal increased the glycemic response in healthy subjects and well-controlled noninsulin-dependent diabetic patients, thus suggesting that this effect might be mediated by an altered gastric emptying. Still, no measurements on gastric emptying were done to prove it. Contradictory results indicate that following ingestion of a solid-liquid meal, the stomach retains solid food predominantly in the proximal stomach, until the majority (about $80 \%$ ) of the liquid has emptied [17-19]. The gastric response to water added directly into a semisolid meal is less well studied and might involve different mechanisms for gastric emptying than emptying of mixed solids-liquid meals.

Using a standardised ultrasound method, this study was aimed at investigating if the gastric emptying in healthy subjects could be influenced by adding locust been gum to a nutrient semisolid test meal. The effect on gastric emptying by adding water directly into this semisolid test meal was also evaluated.

\section{Methods}

Test meals

Gastric emptying rates of three test meals with different viscosity were evaluated. The temperature of 15 randomly selected test meals was measured immediately prior to ingestion (mean temperature, $21.2 \pm 1.9^{\circ} \mathrm{C}$ ).

\section{Basic test meal}

The basic test meal consisted of $300 \mathrm{~g}$ rice pudding (330 $\mathrm{kcal}$, provided as $10 \%$ protein, $58 \%$ carbohydrate and $32 \%$ fat), (Scan Risgrynsgröt, Scan Foods, Johanneshov, Sweden).

\section{Basic test meal added with Nestargel}

To increase the viscosity of this semisolid basic test meal $6 \mathrm{~g}$ Nestargel $(2.4 \mathrm{kcal})$ was stirred into the basic test meal (rice pudding) homogeneously 2 hours before being served. The increase in viscosity was considerable and visible for the eye. Nestargel (Swedish Nestlé AB, Findus ${ }^{\circledast}$, Bjuv, Sweden), usually used as a milk thickener for infants because of its water-binding capacity, is a low calorie product containing soluble, viscous dietary fibres (96.5\%) provided as seed flour of locust bean gum (St. John's bread), and calciumlactate $(3.5 \%)$. It does not contain gluten and is able to keep its capability to increase the viscosity of the test meal used in this study (rice pudding) despite changes in meal temperatures up to $50^{\circ} \mathrm{C}$.

\section{Basic test meal added with water}

By adding $100 \mathrm{ml}$ of water into the basic test meal, stirred homogeneously 2 hours before being served, a considerable decrease in the viscosity of the test meal was achieved.

\section{Study design}

Fifteen healthy non-smoking volunteers, all from the southern county of Sweden, 6 men and 9 women, aged 18 - 68 years (mean age $35 \pm 17$ years), with normal body mass indices (mean BMI $23.1 \pm 3.0 \mathrm{~kg} / \mathrm{m}^{2}$; range 18.1 $26.8 \mathrm{~kg} / \mathrm{m}^{2}$ ) and without symptoms of gastrointestinal disease, participated in the study. None of the subjects had a prior history of gastrointestinal surgery (except for appendectomy), were on any medication (including birth control medication) or did use snuff. On each study day any current symptoms attributable to the gastrointestinal tract were noted, and the fasting blood glucose checked for normal concentrations using finger-prick capillary blood samples. Subjects reporting temporary abnormal defecation such as constipation or diarrhea [20] were examined on another occasion when these conditions were normalized. At three separate mornings, the subjects were served the test meals in a random order as a breakfast, after an overnight fast ( 8 hours). The test meals were ingested within five minutes and the ultrasound examinations were done in the same room between 8:00 and 10:00 AM. All subjects obtained written information prior 
to the study and were aware of the possibility of withdrawing from the study at any time they desired.

\section{Measurement of gastric emptying rate}

Gastric emptying was assessed using a previously described standardized ultrasound method [21,22]. The subjects were examined with a Hitachi EBU 400 (Hitachi, Tarrytown, NY) ultrasound instrument with an abdominal 3.5 MHz transducer. Two examiners assessed all 15 subjects and, for the examiners, the study was double blind with respect to the test products. When studied, all subjects were in a supine position with the ultrasound transducer applied with minimal abdominal compression, but between the examinations the subjects were resting seated in a chair. Gastric emptying was monitored indirectly by determining the longitudinal $\left(D_{1}\right)$ and anteroposterior $\left(\mathrm{D}_{2}\right)$ diameters of a single section of the gastric antrum. The intragastric volume was assumed to be directly proportional to the cross-sectional area of the antrum [23], which was measured at the longitudinal scan at the level of the abdominal aorta and the left lobe of the liver. At each observation three measurements were taken using the mean values of the longitudinal $\left(\mathrm{D}_{1 \text { mean }}\right)$ and anteroposterior $\left(\mathrm{D}_{2 \text { mean }}\right)$ diameters to calculate the antral area. The antral cross-sectional area $\left(\mathrm{A}_{\text {Antrum }}\right)$ was calculated in all subjects using the following formula:

$\mathrm{A}_{\text {Antrum }}=\Pi \times \mathrm{D}_{1 \text { mean }} \times \mathrm{D}_{2 \text { mean }} / 4$

The measurements of the gastric antrum (on average lasting between 1 - 3 minutes) were taken 15 and 90 minutes after the end of meal ingestion. Gastric emptying rate (GER) was estimated and expressed as the percent reduction in antral cross-sectional area from 15 to 90 minutes calculated as follows:

$\mathrm{GER}=[($ A-area $90 \mathrm{~min} / \mathrm{A}$-area $15 \mathrm{~min})-1] \times 100$

\section{Statistical Analysis}

For each subject and type of test meal the gastric emptying rate (GER) was calculated, and the values presented as median values with range and quartiles $\left(\mathrm{q}_{1}-\mathrm{q}_{3}\right)$. These data were evaluated using the Wilcoxon signed rank test and statistical analysis were carried out for the GER, using a two-sided test. Values of $p<0.05$ were considered significant. The median changes of the GER ( $\Delta$ median) for the rice pudding after increasing $\left(\Delta\right.$ median $\left.^{\mathrm{i}}\right) /$ decreasing $\left(\Delta\right.$ median $\left.^{\mathrm{d}}\right)$ the viscosity were calculated and expressed with ranges. All statistical calculations were performed in SigmaStat 2.0 for Windows ${ }^{\circledast}$.

\section{Results}

The median value of GER with the basic test meal (rice pudding) was estimated at $63 \%$, (range 47 to $84 \%),\left(\mathrm{q}_{1}\right.$ $\left.=61 \%, q_{3}=69 \%\right)$. Increasing the viscosity of the rice pud- ding by adding Nestargel, resulted in significantly lower gastric emptying rates $(p<0.01)$, median GER $54 \%$, (range 7 to $71 \%$ ), $\left(\mathrm{q}_{1}=48 \%, \mathrm{q}_{3}=60 \%\right.$ ), (Figure 1 ). Individual GER values showed a decreased gastric emptying in all but two subjects and a median decrease in GER with 11 $\%\left(\Delta\right.$ median $\left.^{\mathrm{i}}=-11 \%\right)$, (range -40 to $\left.16 \%\right)$, after the addition of Nestargel to the rice pudding (Figure 2).

A wide spread in the GER were noted when the viscosity of the rice pudding was decreased (basic test meal added with water), showing higher gastric emptying rates in 6 subjects, still lower rates in 9 subjects (Figure 3). The median change in GER indicated a decrease in GER with 6 $\%\left(\Delta\right.$ median $\left.^{\mathrm{d}}=-6 \%\right)$, (range -23 to $\left.24 \%\right)$, but the difference in GER $65 \%$, (range 38 to $79 \%$ ), $\left(\mathrm{q}_{1}=56 \%, \mathrm{q}_{3}=71\right.$ $\%)$ was nonsignificant $(p=0.28)$ compared to the GER of the basic test meal (Figure 1).

\section{Discussion}

This study demonstrates that the addition of locust bean gum but not water significantly influences the gastric emptying rate of a nutrient semisolid meal in healthy subjects. Despite the addition of only $6 \mathrm{~g}$ Nestargel to the rice pudding (basic test meal), which is less than $2 \%$ of the total test meal weight, the individual GER values showed a decreased gastric emptying in all but two subjects and a median decrease in GER with $11 \%$ (Figure 2). The effect of locust bean gum agrees with previous results of other viscous fibers, such as pectin and guar gum. Actually, almost all previous studies regarding the effects of gelforming fibers have considered the gastric emptying of liquid or solid meals after the addition of pectin or guar gum. The influence of locust bean gum on gastric emptying of a nutrient semisolid meal in humans has been less well studied previously, despite its common occurrence in foods. Locust bean gum (St. John's bread, carob seed gum), the gum extract from carob seed (Ceratonia siliqua), is widely used as a thickening and stabilizing agent in food (e.g. ice cream, yogurt, mayonnaise, ketchup, marmalades, soups, desserts, sauces, bakery products, processed cheese and other) as well as a pharmaceutics agent (e.g. gastro-oesophageal reflux in infants and children). Since locust bean gum is not digested or absorbed in the stomach or the small bowel and the caloric content in the $6 \mathrm{~g}$ Nestargel (2.4 kcal) added to the basic test meal was minimal, a caloric influence of Nestargel on gastric emptying was interpreted as insignificant in this study. The preparing time and the meal temperature might influence the viscosity of the water soluble fibers in the meal. The preparing procedure was therefore identical each time (the fibers stirred into the rice pudding, without heating, 2 hours before ingestion). Furthermore, the gastric motility might be influenced by meal temperature [4], but as the mean temperature of the test meals used in this study, 


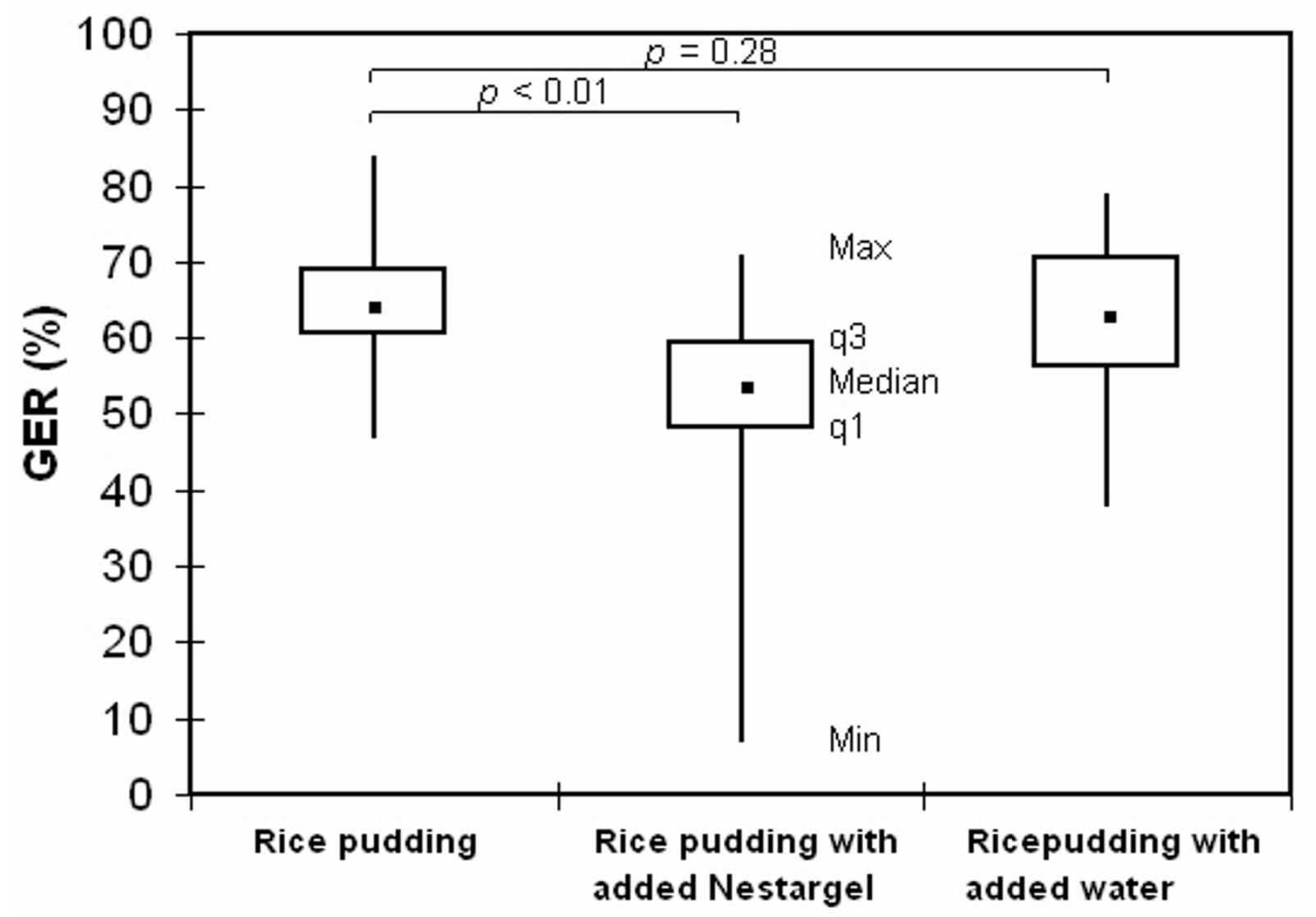

Figure I

Gastric emptying of rice pudding, rice pudding with added Nestargel and rice pudding with added water, estimated as gastric emptying rate (GER), in healthy subjects. The median, minimum (Min), and maximum (Max) values and the values of the first $(q I)$ and third (q3) quartiles are shown. Values of $p<0.05$ were considered significant.

measured immediately prior to ingestion, showed only very slight variation (mean temperature, $21.2 \pm 1.9^{\circ} \mathrm{C}$ ) such a possible influence was interpreted as insignificant.

Locust bean gum has been shown to manage [24] or fail [25] in decreasing the postprandial glucose response in non-insulin-dependent diabetes patients. Previously, it has been shown that the effect of fiber-enriched wheat bran (Fiberform), added to a semisolid meal consisting of wheatmeal porridge and juice, caused an accumulation of the meal within the proximal stomach [26]. Assuming a similar effect of locust bean gum, this might delay the time for the postprandial antral area to reach its maximum value, giving a lower 15 min postprandial antral area and a wider 90 min postprandial antral area, depending on the time necessary for the proximal part of the stomach (the fundus) to deliver the food to the lower part of the stomach (the antrum), consequently reducing the value of the GER. A study on healthy volunteers, using magnetic resonance imaging, showed that the gastric response to increased viscosity of a non-nutrient locust bean gum water solution was rapid intragastric dilution, causing a reduction of the initial large difference in viscosity [27]. This rapid dilution minimized the differences in the gastric emptying rates resulting in a minimal delay of gastric emptying. Despite that viscosity varied 1000-fold between the solutions used in that study, emptying rates differed by a factor of only 1.3. This dilution response was suggested to be either due to salivation or acid secretion. However, the subjects were intubated with a nasogastric tube during the trial and intubation could influence gastric motility [28]. In the present study no intubation technique was used and the meal served, a nutrient semisolid test meal, was more representative of an ordinary break- 


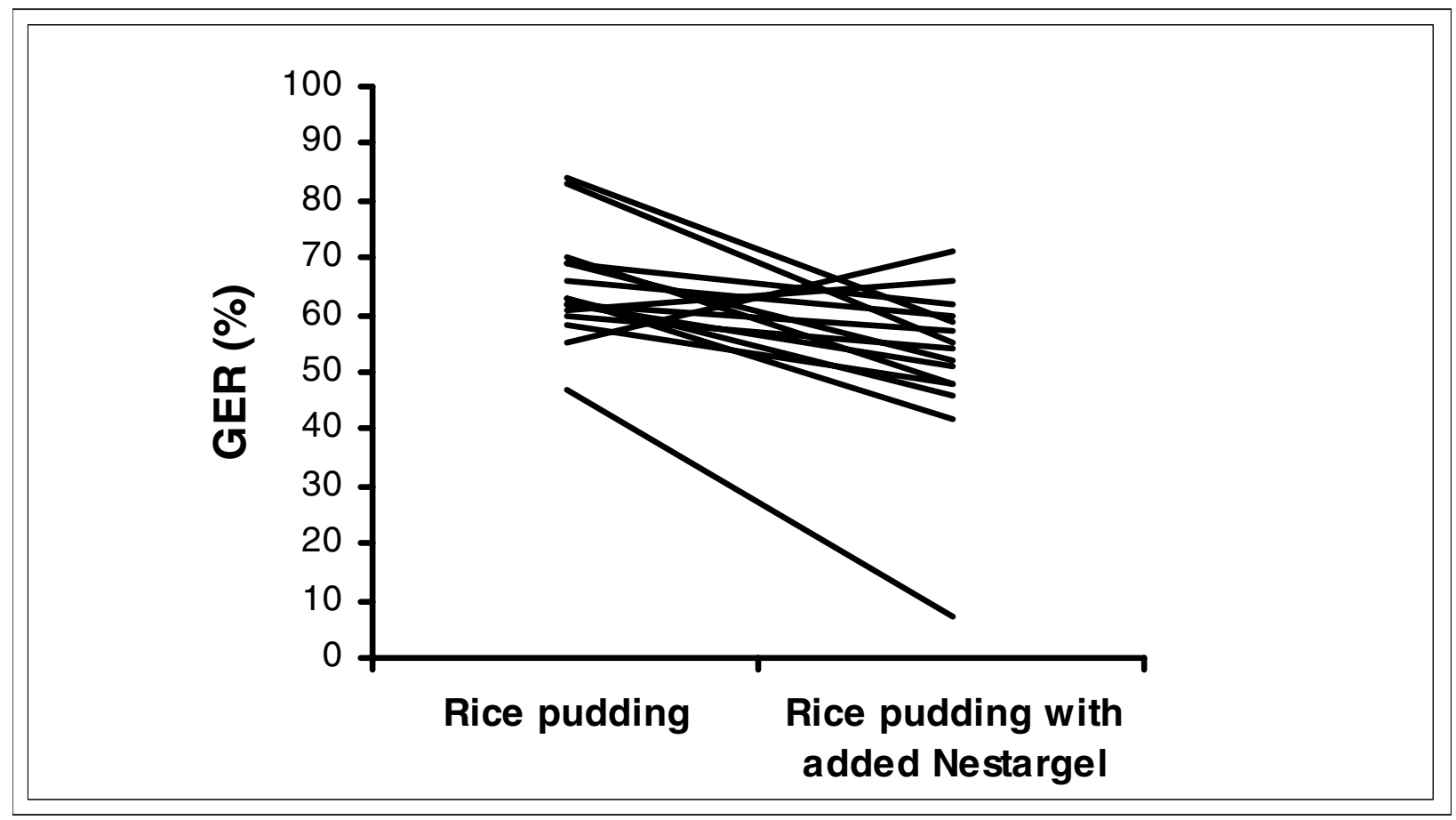

Figure 2

Individual values of gastric emptying of rice pudding and rice pudding with added Nestargel, estimated as gastric emptying rate (GER), in healthy subjects.

fast meal, at least in Sweden. This is an important fact since the increased outflow resistance due to pylorospasm and altered antroduodenal motility probably is much more important in nutrient than non-nutrient meals $[29,30]$. It has been suggested that acid secretion is lower in diabetic patient, probably due to vagal neuropathy $[31,32]$. Such possible differences in gastric juice secretion between diabetic patients, with vagal neuropathy and gastroparesis, and healthy subjects might limit the capability of the stomach to reduce the viscosity of the gastric content resulting in a greater impact of meal viscosity on gastric emptying. Previously it has been claimed that when fiber arrives in the distal ileum or in the colon, it exerts a negative feedback on gastric emptying (the 'ileal brake') $[33,34]$. Similarly, one could expect that the influence of locust bean gum on gastric emptying would be due to duodenal feedback controlling antroduodenal coordina- tion and inhibiting gastric emptying [35], since rapid intragastric dilution decreases meal viscosity. This might be due to delayed absorption of nutrients (e.g. fats) in the duodenum induced by the presence of fibers in the meal [13].

In our study, the addition of $100 \mathrm{ml}$ water to a nutrient semisolid meal did not influence gastric emptying in healthy subjects. The total caloric content of the basic test meal with added water was the same as the one without water $(330 \mathrm{kcal})$, still the results are surprising. Actually, since the volume and nutrient density of a meal are considered to be important factors for the GER [1] we expected the gastric emptying to be increased after the addition of water to the rice pudding, due to increased volume, and decreased caloric density and viscosity. On the other hand, the water volume added to the test meal 


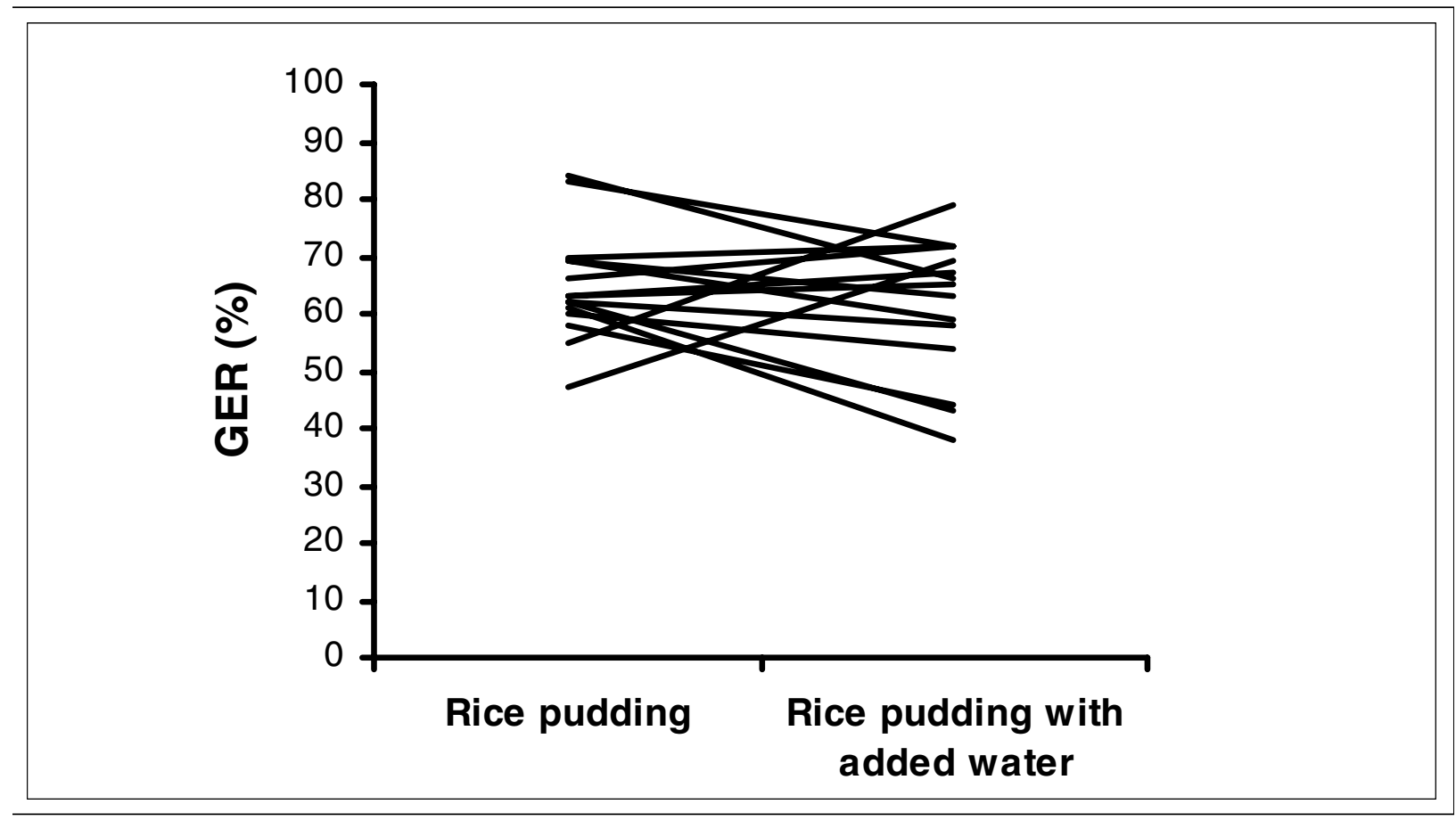

Figure 3

Individual values of gastric emptying of rice pudding and rice pudding with added water, estimated as gastric emptying rate (GER), in healthy subjects.

might have been to small to provoke a change in gastric emptying rate, despite the considerable decrease in viscosity visible for the eye. Also, in the present study the GER vary widely and more for the test meal with added water than the other test meals (Figure 3). We could not explain this difference. Solid foods empties separately, and more slowly, from the stomach than liquids [17-19], while semisolid foods probably empties in a way more like nutrient liquids. Compared to the study by Thorsdottir [16], our study considered the effect on gastric emptying by adding water into a semisolid meal instead of drinking the water together with a solid meal.

We conclude that the addition of locust bean gum to a nutrient semisolid meal has a major impact on gastric emptying by delaying the emptying rate, but that the addition of water to this test meal has no influence on gastric emptying in healthy subjects. Whether similar results occur in patients with gastroparesis and functional dyspepsia remains to be seen since the effects might be different when the gastric motor function is disordered.

\section{Competing interests}

None declared.

\section{Acknowledgement}

The authors thank Jan-Åke Nilsson for valuable advice on the statistical analysis of our data.

\section{References}

I. Horowitz M, Dent J, Fraser R, Sun W and Hebbard G: Role and integration of mechanisms controlling gastric emptying. Dig Dis Sci 1994, 39:7S-13S.

2. Attvall S, Abrahamsson H, Schvarcz E and Berne C: [Gastric emptying is important for the patients with diabetes]. Läkartidningen 92(45):4166, 4169-4I7|-2. I995 Nov 8 
3. Lavigne ME, Wiley ZD, Meyer JH, Martin P and MacGregor IL: Gastric emptying rates of solid food in relation to body size. Gastroenterology 1978, 74(6): | 258-60.

4. Sun WM, Penagini R and Hebbard G: Effect of drink temperature on antropyloroduodenal motility and gastric electrical activity in humans. Gut 1995, 37(3):329-34.

5. Scott AM, Kellow JE, Shuter B, Nolan JM, Hoschl R and Jones MP. Effects of cigarette smoking on solid and liquid intragastric distribution and gastric emptying. Gastroenterology 1993, 104(2):410-6.

6. Smith U: Dietary fibre, diabetes and obesity. Int J Obes 1987, I I(Suppl I):27-3I.

7. Jenkins $D J$ and Jenkins $A L$ : Dietary fiber and the glycemic response. Proc Soc Exp Biol Med 1985, I 80(3):422-3I.

8. Ray TK, Mansell KM, Knight LC, Malmud LS, Owen OE and Boden G: Long-term effects of dietary fiber on glucose tolerance and gastric emptying in noninsulin-dependent diabetic patients. Am J Clin Nutr 1983, 37(3):376-8I.

9. Blackburn NA, Holgate AM and Read NW: Does guar gum improve post-prandial hyperglycaemia in humans by reducing small intestinal contact area? Br J Nutr 1984, 52(2): 197-204.

10. Schwartz SE, Levine RA, Weinstock RS, Petokas S, Mills CA and Thomas FD: Sustained pectin ingestion: effect on gastric emptying and glucose tolerance in non-insulin-dependent diabetic patients. Am J Clin Nutr 1988, 48(6): I4 I3-7.

II. Torsdottir I, Alpsten M, Andersson H and Einarsson S: Dietary guar gum effects on postprandial blood glucose, insulin and hydroxyproline in humans. J Nutr 1989, I I 9(12): 1925-31.

12. Leclere CJ, Champ M and Boillot J: Role of viscous guar gums in lowering the glycemic response after a solid meal. Am J Clin Nutr 1994, 59(4):914-21.

13. Benini L, Castellani $G$ and Brighenti F: Gastric emptying of a solid meal is accelerated by the removal of dietary fibre naturally present in food. Gut 1995, 36(6):825-30.

14. Blackburn NA, Redfern JS and Jarjis $\mathrm{H}$ : The mechanism of action of guar gum in improving glucose tolerance in man. Clin $\mathrm{Sc}$ (Lond) 1984, 66(3):329-36.

15. Flourie B, Vidon N, Florent $\mathrm{CH}$ and Bernier J]: Effect of pectin on jejunal glucose absorption and unstirred layer thickness in normal man. Gut 1984, 25(9):936-41.

16. Torsdottir I and Andersson H: Effect on the postprandial glycaemic level of the addition of water to a meal ingested by healthy subjects and type 2 (non-insulin-dependent) diabetic patients. Diabetologia 1989, 32(4):23I-5.

17. Collins PJ, Horowitz M, Cook DJ, Harding PE and Shearman DJ: Gastric emptying in normal subjects - a reproducible technique using a single scintillation camera and computer system. Gut I 983, 24(I 2): I | I7-25.

18. Camilleri M, Malagelada JR, Brown ML, Becker G and Zinsmeister AR: Relation between antral motility and gastric emptying of solids and liquids in humans. Am J Physiol I985, 249(5 Pt I):G580-5.

19. Houghton LA, Read NW and Heddle R: Relationship of the motor activity of the antrum, pylorus, and duodenum to gastric emptying of a solid-liquid mixed meal. Gastroenterology 1988, 94(6): $|285-9|$.

20. Powell DW: Approach to the Patient With Diarrhea. In Textbook of Gastroenterology secondth edition. Edited by: Yamada T. JB Lippincott Company, Philadelphia; 1995:813.

21. Darwiche G, Almer LO, Bjorgell O, Cederholm C and Nilsson P: Measurement of gastric emptying by standardized real-time ultrasonography in healthy subjects and diabetic patients. J Ultrasound Med 1999, 18(10):673-82.

22. Darwiche G, Björgell O, Thorsson O and Almer LO: Correlation between simultaneous scintigraphic and ultrasonographic measurement of gastric emptying in patients with type I diabetes mellitus. J Ultrasound Med 2003, 22:459-66.

23. Ricci R, Bontempo I, Corazziari E, La Bella A and Torsoli A: Rea time ultrasonography of the gastric antrum. Gut 1993, 34(2): $173-6$.

24. Feldman N, Norenberg $\mathrm{C}$, Voet $\mathrm{H}$, Manor E, Berner $\mathrm{Y}$ and Madar $\mathrm{Z}$. Enrichment of an Israeli ethnic food with fibres and their effects on the glycaemic and insulinaemic responses in subjects with non-insulin-dependent diabetes mellitus. $\mathrm{Br} J \mathrm{Nutr}$ 1995, 74(5):68I-8.
25. Williams DR, James WP and Evans IE: Dietary fibre supplementation of a 'normal' breakfast administered to diabetics. Diabetologia 1980, 18(5):379-83.

26. Rydning A, Berstad A, Berstad T and Hertzenberg L: The effect of guar gum and fiber-enriched wheat bran on gastric emptying of a semisolid meal in healthy subjects. Scand J Gastroenterol 1985, 20(3):330-4.

27. Marciani L, Gowland PA and Spiller RC: Gastric response to increased meal viscosity assessed by echo-planar magnetic resonance imaging in humans. J Nutr 2000, I30(I):122-7.

28. Quigley EM, Donovan JP, Lane MJ and Gallagher TF: Antroduodenal manometry. Usefulness and limitations as an outpatient study. Dig Dis Sci 1992, 37(1):20-8.

29. Heddle R, Dent J and Read NW: Antropyloroduodenal motor responses to intraduodenal lipid infusion in healthy volunteers. Am J Physiol I988, 254(5 Pt I):G67I-9.

30. Brener W, Hendrix TR and McHugh PR: Regulation of the gastric emptying of glucose. Gastroenterology 1983, 85(I):76-82.

31. Buysschaert M, Donckier J, Dive A, Ketelslegers JM and Lambert AE: Gastric acid and pancreatic polypeptide responses to sham feeding are impaired in diabetic subjects with autonomic neuropathy. Diabetes 1985, 34(I I): I I8I-5.

32. Hosking DJ, Moody F, Stewart IM and Atkinson M: Vagal impairment of gastric secretion in diabetic autonomic neuropathy. $\mathrm{Br}$ Med J 1975, 2(597 I):588-90. I975 Jun I4

33. Lin HC, Moller NA, Wolinsky MM, Kim BH, Doty JE and Meyer JH: Sustained slowing effect of lentils on gastric emptying of solids in humans and dogs. Gastroenterology 1992, $102(3): 787-92$.

34. Stephen $A M$ and Cummings $\mathrm{JH}$ : Mechanism of action of dietary fibre in the human colon. Nature 284(5753):283-4. 1980 Mar 20

35. Horowitz $M$ and Fraser $R$ : Disordered gastric motor function in diabetes mellitus. Diabetologia 1994, 37(6):543-5I.

\section{Pre-publication history}

The pre-publication history for this paper can be accessed here:

\section{http://www.biomedcentral.com/1471-230X/3/12/pre-} pub
Publish with Bio Med Central and every scientist can read your work free of charge

"BioMed Central will be the most significant development for disseminating the results of biomedical research in our lifetime. "

Sir Paul Nurse, Cancer Research UK

Your research papers will be:

- available free of charge to the entire biomedical community

- peer reviewed and published immediately upon acceptance

- cited in PubMed and archived on PubMed Central

- yours - you keep the copyright
BioMedcentral 